\title{
A Comparative Analysis of Subjective Quality of the Mobility between a New Portable Electric Transportation Mode and Walking
}

\author{
Hiroyuki Ohta, ${ }^{1,2}$ Haruyuki Matsumoto, ${ }^{1}$ Daisuke Fukuda, ${ }^{1}$ and Satoshi Fujii ${ }^{3}$ \\ ${ }^{1}$ Department of Civil and Environmental Engineering, Tokyo Institute of Technology, 2-12-1 Ookayama, Meguro-ku, \\ Tokyo 152-8552, Japan \\ ${ }^{2}$ Ports and Harbours Bureau, Ministry of Land, Infrastructure, Transport and Tourism, 2-1-3 Kasumigaseki, Chiyoda-ku, \\ Tokyo 100-8918, Japan \\ ${ }^{3}$ Department of Urban Management, Kyoto University, Kyoto Daigaku Katsura 4, Nishikyō-ku, Kyoto 615-8540, Japan
}

Correspondence should be addressed to Hiroyuki Ohta, otaota812@yahoo.co.jp

Received 27 July 2012; Accepted 29 November 2012

Academic Editor: Motoyuki Akamatsu

Copyright (๑) 2012 Hiroyuki Ohta et al. This is an open access article distributed under the Creative Commons Attribution License, which permits unrestricted use, distribution, and reproduction in any medium, provided the original work is properly cited.

To analyze the psychological impacts of the introduction of new portable electric transportation modes, we implemented an experiment using a personal mobile vehicle (PMV). We investigated its effects on 2 types of the subjective quality of mobility (SQM): instrumental aspects including "easiness" and "speed": and affective aspects including "enjoyment," "seeing scenery," and "enjoying the atmosphere." The result indicated that PMV might contribute to the improvement of the instrumental aspects of SQM, but walking was regarded as more preferable in terms of the affective aspects. The results suggest that such a new transportation mode could contribute to the improvement of subjective quality of mobility, if and only if it can be introduced in an appropriate situation.

\section{Introduction}

In the recent years, various personal mobility devices (PMDs) such as powered wheel chairs, scooters, and Segways have been developed with needs for high personal mobility in the aged society and for mitigating the environmental problem and so forth, since PMDs might be alternative travel modes to automobile in a short-trip travel. in Japan, especially the Segway has been sold for companies since 2006; "i-real" and "PIXY," which are new PMDs on a conceptual phase, were exhibited at the Tokyo Motor Show 2007. These situations imply that new PMDs might be introduced into our society in the near future.

PMDs might contribute to the improvement of personal mobility, but they could also cause some negative problems such as accidental risk, vehicles' congestion, and health depression. To cope with these problems, Rodier et al. [1] tested the safety of low-speed transportation modes in the pedestrian environment, and Litman [2] suggested an appropriate way to manage some PMDs on nonmotorized facilities including walkways, sidewalks, and paths. Kin et al. $[3,4]$ proposed evaluation items of PMDs considering the human factors in terms of safety and risk and suggested the road assignment for various PMDs It is necessary to ensure the safety of PMDs, or to consider the road space assignment before these new vehicles will come into our society. However, it is still unclear how PMDs would influence the quality of people's mobility. One can assume that there would be various psychological influences in terms of, for instance, comforts or enjoyments.

\section{Quality of Mobility}

2.1. Intrinsic Value of Travel. Travel is not only a derived demand for the activities but also an activity for the travel itself. That means travel is not always regarded as a "cost" to be minimized, but travel has also positive aspects of travel 
TABLE 1: Specification of PMV (in a development phase).

\begin{tabular}{lc}
\hline Weight & $17 \mathrm{~kg}$ \\
Maximum speed & $6 \mathrm{~km} / \mathrm{h}$ \\
Diameter of tire & $15 \mathrm{cmm}$ \\
\hline
\end{tabular}

itself like strolling or driving pleasure. Previous studies showed an importance to distinguish between travel for its own sake and travel for utilitarian purposes and to the possibility that the factors which influence these two categories of travel may differ significantly [5-7]. Anable and Gatersleben [8] examined the relative importance of instrumental and affective factors for work and leisure journeys. From their results, people tend to attach more importance to the instrumental aspects for work journey, while attach almost equal importance to the instrumental and affective aspects for leisure journeys. In addition the enjoyable or favorable travel increased the demand of one's travel according to the studies by Choo et al. [9] and Ory and Mokhtarian [10]. As to short-trip travel that walking is one of the most important transportation modes, Handy [11] indicated that the purpose of many walking trips was the walk itself rather than whatever destination was reached. Cao et al. [12] analyzed the influences of built environment factors and residential self-selection on both types of pedestrian travel: travel for its own sake (strolling) and travel for utilitarian purposes (walking to the store). These studies give us evidences that there would be a significantly difference between travel for its own sake and travel for utilitarian purposes.

From these implications, if PMDs will be introduced and people will come to use it instead of the other modes including walking, both two aspects of travel would be changed. In other words, PMDs could change not only the travel for utilitarian purposes (e.g., improvement of speed), but also travel for its own sake (e.g., driving/walking pleasure). Therefore, it would be important to investigate the psychological impact of PMDs on users for the assessment of introduction of PMDs into an urban transportation system.

In this study, to analyze the psychological impacts of PMDs, we implemented an experiment using "a personal mobile vehicle" (PMV). "PMV" is a new portable electric transportation mode, which is a kind of PMDs, in a development stage with the following: 3 characteristics; (1) it can offer comfortable and short travel with low electric power which is environmental friendly; (2) it can be used safely in the pedestrian area; (3) people can take it along easily in different transportation modes such as bus, train, and car [13]. The specification of PMV used in this study is shown in Table 1, and its virtual image is shown in Figure 1.

2.2. Two Types of Subjective Quality of Mobility (SQM). In this study, we investigated 2 types of subjective quality of mobility (SQM): instrumental SQM including "easiness" and "speed" of mobility and affective SQM including "enjoyment," "seeing scenery," and "enjoying the atmosphere" of mobility. We assumed that instrumental SQM might be more important when people perceived a travel as a derived

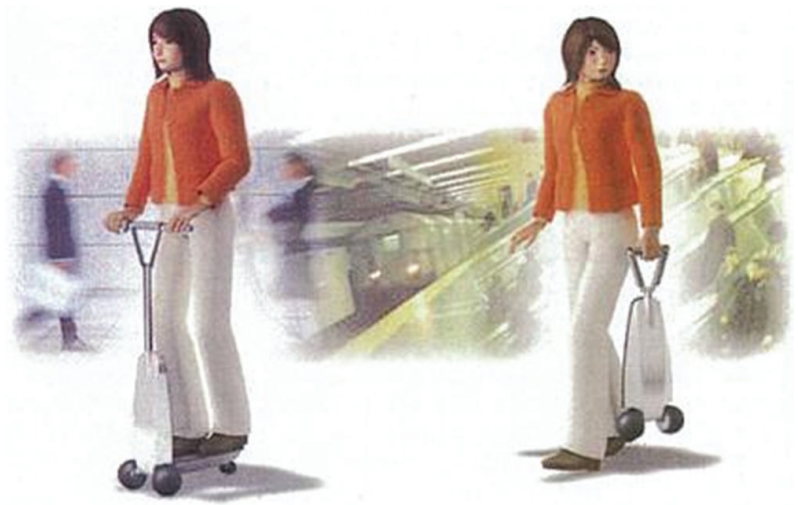

FIgURE 1: Virtual image of PMV.

demand, for instance, an access to a destination. On the other hand affective SQM might be more important when people enjoy a travel for its own sake, for example, a stroll around.

\section{Method}

We implemented an experiment at Tokyo University in late February 2007. 30 students (15 males and 15 females) and 32 workers ( 15 males and 17 females) were gathered from Tokyo Institute of Technology and Tokyo University. At first participants tried to drive PMV with an instruction by a trainer in 5 minutes, and then, they drove it freely in 10 minutes. After that, they moved to another room, and then, answered a questionnaire about the quality of mobility. Note that all participants had never experienced PMV.

3.1. Process in the Questionnaire. In the questionnaire, 4 types of different situations were described and questions regarding SQM in the situations were asked, respectively. The 4 types of different situations were as follows (1) access to the nearest restaurant from home, (2) stroll in the shopping area, (3) stroll in the city park, and (4) move in the airport.

As to "access to the nearest restaurant from home," we defined the nearest distance as from $500 \mathrm{~m}$ to $1 \mathrm{~km}$ and then asked about the participants, frequency to the nearest restaurant that they actually use. If they do not use any restaurant near their home, they were asked not to answer the questions regarding this situation. Note that the restaurant does not include "fast food shop" and "pub." As to "stroll in the shopping area" and "stroll in the city park," we provided sample pictures and then asked the participants to image similar place before questions. As to "move in the airport," we asked the frequency in use of most commonly used airport, and if someone never used an airport, we asked them not to answer the question about "move in the airport."

3.2. Measures. In the questionnaire participants were asked 3 questions regarding SQM, (1) the importance of different types of SQM in the situation, (2) different types of SQM for different modes in the situation, and (3) attitudes toward travel in the situations by different modes. In this study, 
TABLE 2: Evaluation criteria of SQM.

\begin{tabular}{lll}
\hline & Importance of SQM & SQM for each transportation mode \\
\hline Easiness & How easy you can travel & I can travel easy \\
Speed & How fast you can travel & I can travel fast \\
Enjoyment & How you can enjoy when traveling & I can enjoy when traveling \\
Scenery & How you can see various sceneries when traveling & I can see various sceneries when traveling \\
Atmosphere & How you can enjoy the atmosphere when traveling & I can enjoy the atmosphere when traveling \\
\hline
\end{tabular}

TABLE 3: Means and standard deviations (SD) of the importance of SQMs in each situation.

\begin{tabular}{|c|c|c|c|c|c|c|c|c|c|c|}
\hline & \multicolumn{2}{|c|}{ Easiness } & \multicolumn{2}{|c|}{ Speed } & \multicolumn{2}{|c|}{ Enjoyment } & \multicolumn{2}{|c|}{ Scenery } & \multicolumn{2}{|c|}{ Atmosphere } \\
\hline & Mean & $(\mathrm{SD})$ & Mean & $(\mathrm{SD})$ & Mean & $(\mathrm{SD})$ & Mean & $(\mathrm{SD})$ & Mean & $(\mathrm{SD})$ \\
\hline Access to the restaurant $(N=58)$ & 5.81 & $(2.19)$ & 4.36 & $(2.32)$ & 2.60 & $(2.09)$ & 2.16 & $(2.27)$ & 1.88 & $(1.97)$ \\
\hline Move in the airport $(N=58)$ & 6.38 & $(0.85)$ & 6.10 & $(1.36)$ & 1.60 & $(1.70)$ & 1.52 & $(1.81)$ & 1.71 & $(1.67)$ \\
\hline Stroll in the shopping area $(N=61)$ & 4.07 & $(2.50)$ & 0.89 & $(1.53)$ & 4.83 & $(2.07)$ & 5.07 & $(1.80)$ & 5.20 & $(1.89)$ \\
\hline Stroll in the city park $(N=61)$ & 2.52 & $(2.36)$ & 0.39 & $(0.95)$ & 5.54 & $(1.44)$ & 6.23 & $(1.01)$ & 5.97 & (1.14) \\
\hline
\end{tabular}

walking and PMV were selected as competitive transportation modes because the fundamental concept of PMV is that it would be primarily used in the pedestrian area. Only in case of the analysis about the access to the nearest restaurant, we added an automobile for a transportation mode because people can use it only in this case and access to a destination faster than any other private vehicles such as a bicycle and a motorcycle.

3.2.1. Importance of $S Q M s$. We measured the importance of different types of SQM by using 5 evaluation criteria (easiness, speed, enjoyment, scenery, and atmosphere; see Table 2 for definitions) in each situation. Among these 5 criteria, we regarded easiness and speed as instrumental SQMs, and the others (enjoyment, scenery, and atmosphere) as affective SQMs. I asked the participants "How important are the following 5 criteria in this situation?" with the following instructions: "(1) select the criterion which you think the most important and rate it as on 7-point; (2) select the criteria which you do not think important at all and rate it as on 0-point; (3) make ratings the other criteria on numerical 6-point scale with verbal endpoints $(1=$ a little important, 3 = important, 6 = very important)."

3.2.2. SQM for Different Transportation Modes. After asking the importance of SQM, we asked 5 types of SQM (easiness, speed, enjoyment, scenery, and atmosphere) for each transportation mode in the situation. By using items shown in Table 2, I asked participants to make ratings on numerical 5 -point scale with verbal endpoints $(1=$ do not agree at all, 3 $=$ neutral, $5=$ strongly agree) for each transportation mode.

3.2.3. Attitude toward Travel. We then measured two kinds of attitudes toward travel for each transportation mode in the situation. In case of "move in the airport" and "access to the nearest restaurant," we measured "negative attitude toward travel" by asking the participants to make ratings on a numerical 5-point scale with verbal endpoints $(1=$ do not agree at all, $3=$ neutral, $5=$ strongly agree), as follows .
"If possible, I do not want to make this travel." On the other hand, in case of "stroll in the city park" and "stroll in the shopping area," these travels might be regarded as enjoyable travels for their own sake. Therefore, we used different measures for these situations, that is, for "intention to continue travel" by asking the participants to make ratings on a numerical 5-point scale with verbal endpoints $(1=$ do not agree at all, 3 = neutral, $5=$ strongly agree), as follows. "I want to continue this trip". Note that both types of attitudes toward travel were measured for "move in the airport" because this travel might be regarded as an enjoyable one as well as a derived demand to reach the destination.

\section{Results}

4.1. Differences in the Importance of SQM. Table 3 shows the means of the importance of SQMs for the 5 criteria in each situation. Table 3 indicates that in case of "move in the airport" and "access to the nearest restaurant from home," means of "easiness" and "speed" were relatively high, while "enjoyment," "scenery," and "atmosphere" were relatively low. That is, instrumental aspects are more important than affective aspects for these travels. On the other hand, in case of "stroll in the city park" and "stroll in the shopping area," means of "enjoyment," "scenery," and "atmosphere" were relatively high, while means of "easiness" and "speed" were relatively low. as to "speed" especially the, means were less than 1.0; therefore, "speed" has very little importance for these travels. In addition, the instrumental aspects were the highest and the affective aspects were the lowest in case of "move in the airport", "atmosphere" has the highest importance in case of "stroll in the shopping area," and "scenery" has the highest importance in case of "stroll in the city park.”

4.2. Effects of Transportation Modes on SQM. Table 4 shows repeated measures analysis of variance (ANOVA) results revealing that there were statistically significant differences between transportation modes for every SQM except for 
TABLE 4: ANOVA results for SQMs among the transportation modes.

\begin{tabular}{lccccc}
\hline & Easiness & Speed & Enjoyment & Scenery & Atmosphere \\
\hline Access to the restaurant & $F(2,114)=4.61^{*}$ & $F(2,114)=40.17^{* *}$ & $F(2,114)=21.59^{* *}$ & $F(2,114)=31.99^{* *}$ & $F(2,114)=2.28$ \\
Move in the airport & $F(1,57)=53.17^{* *}$ & $F(1,56)=59.27^{* *}$ & $F(1,56)=12.82^{* *}$ & $F(1,57)=9.38^{* *}$ & $F(1,57)=13.25^{* *}$ \\
Stroll in the shopping area & $F(1,60)=10.92^{* *}$ & $F(1,60)=42.87^{* *}$ & $F(1,60)=6.22^{*}$ & $F(1,60)=131.8^{* *}$ & $F(1,60)=86.40^{* *}$ \\
Stroll in the city park & $F(1,60)=25.36^{* *}$ & $F(1,60)=109.8^{* *}$ & $F(1,60)=5.36^{*}$ & $F(1,60)=109.3^{* *}$ & $F(1,60)=59.66^{* *}$ \\
\hline
\end{tabular}
${ }^{*} P<.05,{ }^{*} P<.01$

TABLE 5: Means and standard deviations (SDs) of SQMs for each transportation mode.

\begin{tabular}{|c|c|c|c|c|c|c|c|c|c|c|}
\hline & \multicolumn{2}{|c|}{ Easiness } & \multicolumn{2}{|c|}{ Speed } & \multicolumn{2}{|c|}{ Enjoyment } & \multicolumn{2}{|c|}{ Scenery } & \multicolumn{2}{|c|}{ Atmosphere } \\
\hline & Mean & $(\mathrm{SD})$ & Mean & $(\mathrm{SD})$ & Mean & $(\mathrm{SD})$ & Mean & $(\mathrm{SD})$ & Mean & $(\mathrm{SD})$ \\
\hline & \multicolumn{10}{|c|}{ Access to the restaurant $(N=58)$} \\
\hline Walking & 3.41 & $(1.35)$ & 2.55 & $(1.27)$ & 3.40 & $(1.11)$ & 3.95 & $(1.13)$ & 3.26 & $(1.28)$ \\
\hline PMV & 4.02 & $(1.08)$ & 3.84 & $(1.11)$ & 4.17 & $(0.96)$ & 2.72 & $(1.07)$ & 3.07 & $(1.11)$ \\
\hline \multirow[t]{2}{*}{ Automobile } & 4.02 & $(1.29)$ & 4.36 & $(1.05)$ & 2.98 & $(1.03)$ & 2.64 & $(1.10)$ & 2.81 & $(1.07)$ \\
\hline & \multicolumn{10}{|c|}{ Move in the airport $(N=58)^{\dagger}$} \\
\hline Walking & 2.45 & $(1.43)$ & 2.25 & $(1.35)$ & 2.81 & $(1.11)$ & 3.22 & $(1.31)$ & 3.24 & $(1.16)$ \\
\hline \multirow[t]{2}{*}{ PMV } & 4.29 & $(1.14)$ & 4.21 & $(1.16)$ & 3.47 & $(1.02)$ & 2.59 & $(1.04)$ & 2.59 & $(1.03)$ \\
\hline & \multicolumn{10}{|c|}{ Stroll in the shopping area $(N=61)$} \\
\hline Walking & 3.48 & $(1.16)$ & 2.33 & $(0.98)$ & 4.21 & $(0.88)$ & 4.51 & $(0.67)$ & 4.33 & $(0.65)$ \\
\hline \multirow[t]{2}{*}{ PMV } & 4.15 & $(1.03)$ & 3.69 & $(1.19)$ & 3.79 & $(1.03)$ & 2.77 & $(1.06)$ & 2.95 & $(1.01)$ \\
\hline & \multicolumn{10}{|c|}{ Stroll in the city park $(N=61)$} \\
\hline Walking & 3.18 & $(1.10)$ & 2.03 & $(0.86)$ & 4.33 & $(0.63)$ & 4.80 & $(0.40)$ & 4.66 & $(0.57)$ \\
\hline PMV & 4.21 & $(0.91)$ & 3.98 & $(1.13)$ & 4.00 & $(1.00)$ & 3.23 & (1.17) & 3.28 & $(1.28)$ \\
\hline
\end{tabular}

${ }^{\dagger} N=57$ for "speed" and "enjoyment" in case of "move in the airport" due to missing value.

TAble 6: Means and standard deviations (SDs) of the negative attitude toward travel.

\begin{tabular}{lcc}
\hline & Mean & $(\mathrm{SD})$ \\
\hline & Access to the restaurant $(N=58)$ & \\
\hline Walking & 2.33 & 1.22 \\
PMV & 1.93 & 1.11 \\
Automobile & 2.64 & 1.22 \\
\hline \multicolumn{4}{l}{ Walking } & Move in the airport $(N=58)$ & \\
PMV & 3.59 & 1.24 \\
\hline
\end{tabular}

"enjoying the atmosphere" in case of "access to the nearest restaurant from home." Table 5 shows the means of SQMs for each transportation mode in each situation. As can be seen Table 5, the means of instrumental SQMs such as "easiness" and "speed" for PMV and automobile were higher than that for walking, whereas, the means of affective SQMs such as "scenery" and "atmosphere" for walking were higher than that for PMV and an automobile.

As to "enjoyment," when instrumental SQMs are important such as "move in the airport" and "access to the nearest restaurant from home," means for PMV were higher than that for walking. On the other hand, when affective SQMs are important such as "stroll in the city park" and "stroll in the shopping area," means for walking were higher than
TABle 7: Means and standard deviations (SDs) of the intention to continue the travel.

\begin{tabular}{lcc}
\hline & Mean & $(\mathrm{SD})$ \\
\hline & Stroll in the shopping area $(N=61)$ & \\
\hline Walking & 3.80 & 0.98 \\
PMV & 3.44 & 1.07 \\
\hline \multicolumn{4}{c}{ Stroll in the city park $(N=61)$} \\
\hline Walking & 4.23 \\
PMV & 3.54 & 0.74 \\
\hline & Move in the airport $(N=58)$ & 1.21 \\
\hline Walking & 2.29 \\
PMV & 3.19 & 1.03 \\
\hline
\end{tabular}

that for PMV. In addition the means for an automobile were the lowest in case of "access to the nearest restaurant from home."

4.3. Difference in the Attitude toward Travel. Table 6 shows means of "negative attitude toward travel" and Table 7 shows means of "intention to continue the travel." Repeated measures ANOVA results showed that there were statistically significant differences between transportation modes for the "negative attitude toward travel" in both cases and for the "intention to continue the travel" in case of "stroll in the city park" and "move in the airport" $(P<.01)$, while marginal 
differences in case of "stroll in the shopping area" $(P<.10)$. As can be seen from Table 6, means of the "negative attitude toward travel" for PMV were lower than other modes in case of "move in the airport" and "access to the nearest restaurant from home." In addition the mean for the automobile was the highest. Table 7 indicates that the means of "intention to continue the travel" for walking were higher than that for PMV in case of "stroll in the city park" and "stroll in the shopping area," but the result was opposite in case of "move in the airport." To sum up, the attitude toward travel for PMV was better than walking in case of "move in the airport" and "access to the nearest restaurant from home," whereas walking was better in case of "stroll in the city park" and "stroll in the shopping area."

\section{Discussion}

In this study we investigated 2 types of SQM through the experiment using PMV. The data showed that participants thought the instrumental SQMs were important in case of "move in the airport" and "access to the nearest restaurant from home," while affective SQMs were important in case of "stroll in the shopping area" and "stroll in the city park." Thus the importance of SQM was different between situations. "Move in the airport" and "access to the restaurant from home" might be a derived demand whereas "stroll in the park" and "stroll in the shopping area" might have an intrinsic positive utility. That is, it can be considered that the former is an instrumental-purpose travel, and the latter is an affective-purpose travel.

As to SQM for each transportation mode, PMV could gain the advantage in the instrumental-purpose travel, while walking might dominate in the affective-purpose travel. As well, regarding "attitude toward travel," "intention to continue mobility," and "enjoyment" (one of SQMs), evaluations of PMV were better than walking in the instrumentalpurpose travel, while evaluations of walking were better than PMV in the affective-purpose travel. attitude toward travel for "move in the airport" was especially worse than "access to the nearest restaurant from home," and this travel had the lowest importance of affective SQMs. This means that this travel may be cognitive as a cost to be minimized (i.e., a derived demand), and people may want to reduce it as much as possible. Therefore "enjoyment" for PMV, whose evaluation was higher than "speed" and "easiness," indicated higher value than that for walking. In addition "enjoyment" for an automobile was the lowest, so that this transportation mode may be unsuitable for this kind of travel. In case of "stroll in the shopping area" and "stroll in the city park", "intention to continue the travel" were higher than 3.0 (midvalue), and people attached importance to affective SQMs whereas they do not attached importance to instrumental SQMs. Thus these travels have positive value themselves, so that they do not expect to shorten these travels. Also note that "atmosphere" was most important in the shopping area, whereas "scenery" was the most important in the city park.

These results imply that the shift from walking to PMV might lead to improvement of the instrumental SQMs such as "easiness" and "speed"; therefore "enjoyment" was enhanced and the negative attitude was restrained. From this standpoint, PMV might be introduced into important instrumental-purpose travel such as "move in the airport", where people consider the travel as just only means. On the other hand, the affective SQMs such as "scenery" and "atmosphere" for PMV were lower than that for walking. in affective-purpose travel, "enjoyment" and "intention to continue the travel" for PMV were also lower. Therefore introduction of PMV especially might not be suitable in this kind of situation. That is, walking is the best way for the affective-purpose travel such as "stroll in the shopping area" or "stroll in the city park," where people considered the travel as its own value. These results, of course, depend on the experimental conditions in this study. Therefore, it is unclear when and where the same result can be obtained. For example, since participants in this study have never experienced PMV, the results might be different if they were well trained due to learning effects. However, based on the results that participants feel easier to drive PMV than walking (in Table 5), similar results to this study might be obtained even if they are well trained. In any case, the results in this study are expected to imply a certain tendency that PMV is suitable for the instrumental-purpose while walking is suitable for the affective purpose. As we mentioned in the introduction part, since people perceived their travel as not only just means to reach the destination but also enjoyment itself, a policy maker should take notice the possibility that PMV has both positive and negative effects on the meaning of mobility's quality.

\section{References}

[1] C. J. Rodier, S. A. Shaheen, and S. Chung, "Unsafe at any speed?: what the literature says about low-speed modes," Research Report UCD-ITS-RR-03-10, Institute of Transportation Studies, University of California, Davis, Calif, USA, 2003.

[2] T. Litman, "Managing diverse modes and activities on nonmotorized facilities: guidance for practitioners," ITE Journal, vol. 76, no. 6, pp. 20-27, 2006.

[3] T. Kin, K. Shirasaka, and T. Terashima, "A study of evaluation items of personal travel modes for compatibility analysis," Infrastructure Planning Review, vol. 21, no. 3, pp. 769-780, 2004 (Japanese).

[4] T. Kin, N. Suzuki, and T. Terashima, "Diversification of personal travel modes and the problems of compatibility," Infrastructure Planning Review, vol. 20, no. 3, pp. 691-701, 2003 (Japanese).

[5] P. L. Mokhtarian and I. Salomon, "How derived is the demand for travel? Some conceptual and measurement considerations," Transportation Research Part A, vol. 35, no. 8, pp. 695$719,2001$.

[6] P. L. Mokhtarian, I. Salomon, and L. S. Redmond, "Understanding the demand for travel: it's not purely 'derived", Innovation, vol. 14, no. 4, pp. 355-380, 2001.

[7] D. T. Ory and P. L. Mokhtarian, "When is getting there half the fun? Modeling the liking for travel," Transportation Research Part A, vol. 39, no. 2-3, pp. 97-123, 2005.

[8] J. Anable and B. Gatersleben, "All work and no play? The role of instrumental and affective factors in work and leisure 
journeys by different travel modes," Transportation Research Part A, vol. 39, no. 2-3, pp. 163-181, 2005.

[9] S. Choo, G. O. Collantes, and P. L. Mokhtarian, "Wanting to travel, more or less: exploring the determinants of the deficit and surfeit of personal travel," Transportation, vol. 32, no. 2, pp. 135-164, 2005.

[10] D. T. Ory and P. L. Mokhtarian, "Modeling the structural relationships among short-distance travel amounts, perceptions, affections, and desires," Transportation Research Part A, vol. 43, no. 1, pp. 26-43, 2009.

[11] S. L. Handy, "Urban form and pedestrian choices: study of Austin neighborhoods," Transportation Research Record, no. 1552, pp. 135-144, 1996.

[12] X. Cao, S. L. Handy, and P. L. Mokhtarian, "The influences of the built environment and residential self-selection on pedestrian behavior: evidence from Austin, TX," Transportation, vol. 33, no. 1, pp. 1-20, 2006.

[13] H. Matsumoto, D. Fukuda, and S. Fujii, "A fundamental study on the intention of use toward the new portable electric transport mode," in Proceedings of the 36th Meeting on Infrastructure Planning and Management, 2007, (CD-ROM). 

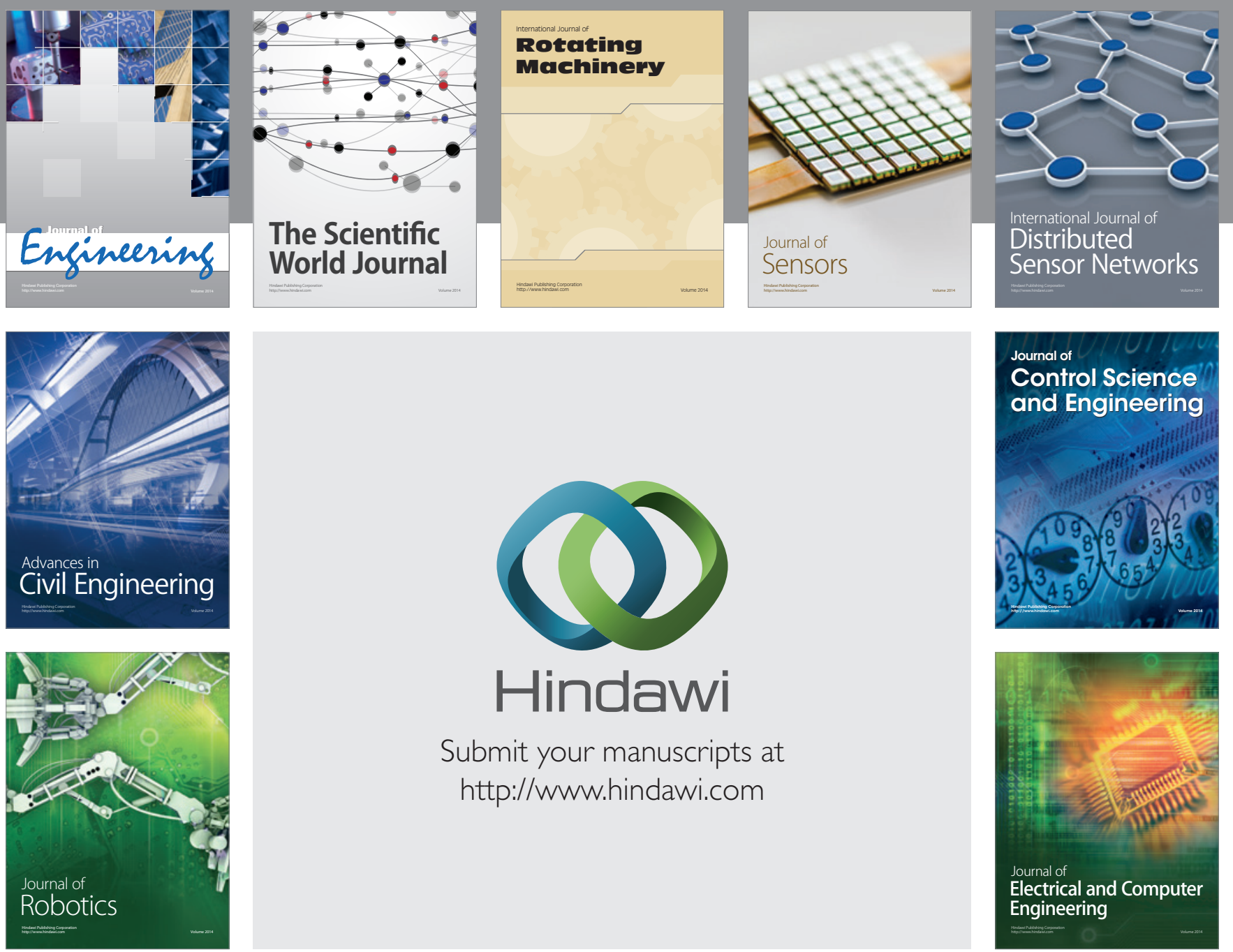

Submit your manuscripts at

http://www.hindawi.com
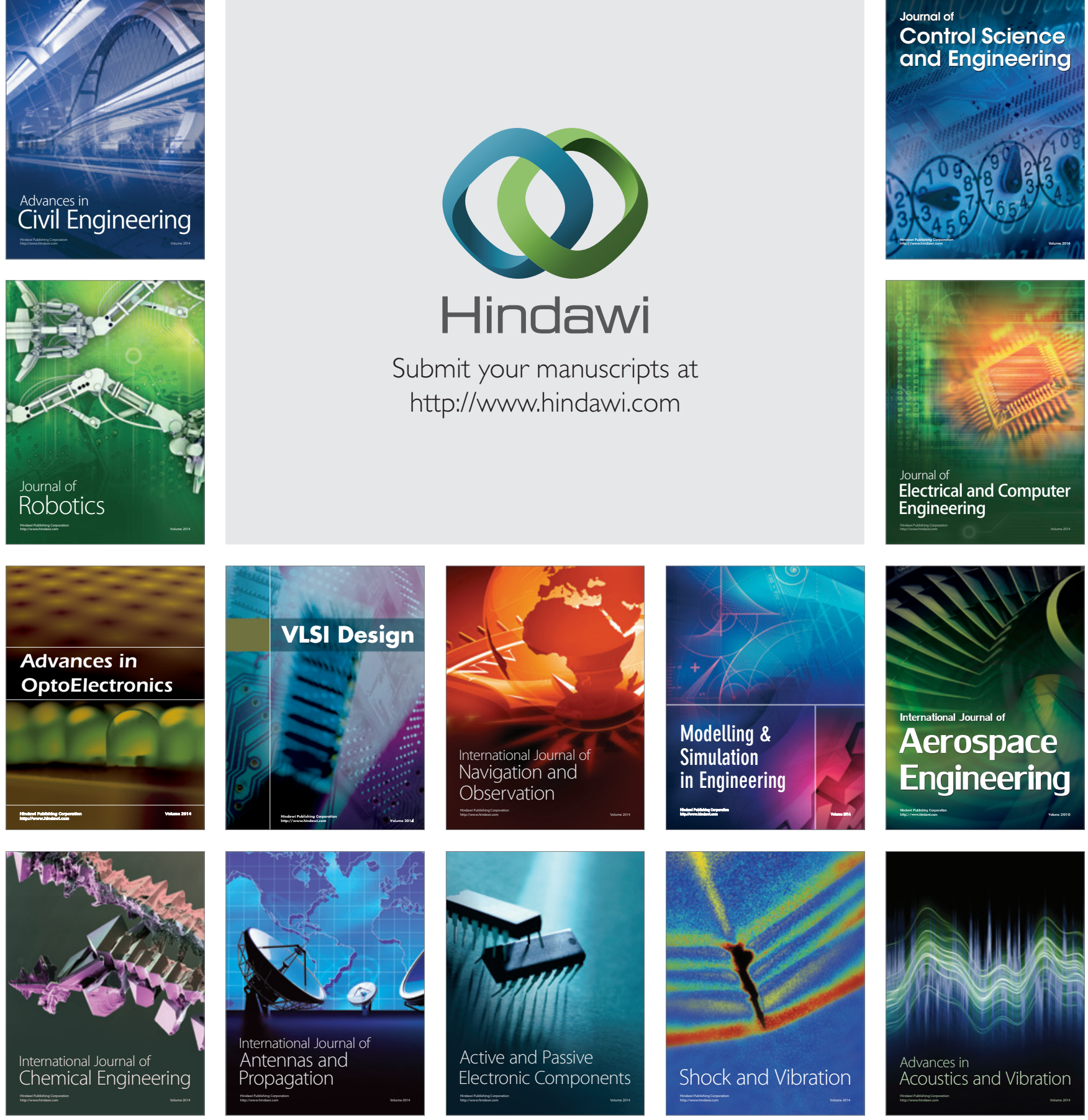